\title{
Selection of effective corrosion inhibitors for bischofite solutions and simulated medium of formation waters
}

\author{
Viktoriia Dmytrenko*, Yuriy Vynnykov, and Ivan Zezekalo \\ National University "Yuri Kondratyuk Poltava Polytechnic", Department of Oil and Gas Engineering and Technology, \\ 24 Pershotravneva Ave., Poltava, 36011, Ukraine
}

\begin{abstract}
Questions of the corrosion inhibitors selection for protection of oil-field pipelines have been studied in the article. Results of research of technological and anticorrosive properties of the corrosion inhibitors in mediums simulating industrial environments are presented. The methodological approaches to selection of the corrosion inhibitors on a stage of laboratory experiments on an example of Kaverdinsky gas-condensate deposites have been described. It was found that all the surfactants tested in the simulated medium of the formation waters show a protective effect of more than $90 \%$ with a dosage of $1 \mathrm{~g} / \mathrm{dm}^{3}$. It is recommended to use bischofite solution with a mass fraction of $24 \% \mathrm{MgCl}_{2}$ and corrosion inhibiting $0.1 \%$ KI-1M admixture to protect industrial gas pipelines from carbon dioxide corrosion. This composition provides a degree of corrosion protection to $99.6 \%$. The results of industrial tests confirmed the effectiveness of complex system - bischofite solution with a mass fraction of $24 \% \mathrm{MgCl}_{2}$ and addition of $0.1 \% \mathrm{KI}-1 \mathrm{M}$ corrosion inhibitor. The cationic surfactants KI-1M, St, SRK and amphoteric surfactants EM and KAPB effectively protect in simulating medium and provide a degree of protection from carbon dioxide corrosion to $91.2-98.9 \%$.
\end{abstract}

\section{Introduction}

Corrosion is one of the main causes of equipment durability in the oil and gas industry, which causes huge economic losses and environmental damage [1-7]. Despite the progress made in combating corrosion destruction of gas equipment, more than 3000 failures of hydrocarbon collection systems pipelines because of internal corrosion are recorded annually.

Repair works of these breakages dramatically increases the cost of operating wells and hydrocarbon collection systems. Neglect of corrosion protection leads to frequent interruptions of work, and in some cases, at break of oil-well tubing to stoppage of hydrocarbon production. The main indirect losses from corrosion are underproduction due to emergency and repair stops, ecological sanctions.

The introduction of advanced technologies for the protection of operational equipment contributes to the reduction of labor and material costs, reducing the duration and cost of repair and rehabilitation works carried out at industrial enterprises [6]. These measures will ensure sustainable future development in the operation of oil and gas fields under conditions of carbon dioxide corrosion.

Important factors affecting degree and nature of corrosion damage are: 1) speed of gas-liquid flow; 2) tensile stresses of tubing; 3) volume ratio of water to hydrocarbon condensates in a liquid phase of flow; 4) inflow into the well of formation waters of different salt composition; 5) influence of organic water-soluble acids $[1,6,7]$.

The mechanism of carbon dioxide corrosion has been studied quite deeply and comprehensively [1, 8-11]. The intensity of corrosive destruction of equipment at $\mathrm{CO}_{2}$ containing deposits is determined by partial pressure of carbon dioxide (at a low content of organic acids) and the temperature at which corrosion process takes place $[1,2,4]$.

During the movement of gas through a wellbore, a liquid phase is released, resulting in a three-phase gas flow of gas-water-hydrocarbon inside the pipes. The intensity of corrosion in a three-phase system is mainly due to the structure and flow regime. Corrosive activity of medium in a well depends on ratio of hydrocarbons to water. According to some researchers, intensive corrosion of equipment begins with content of $0.1 \%$ of water in a well, then the corrosion rate remains constant, although the water content increases.

Key directions for improving corrosion control are use of: 1) inhibitors; 2) new designs and methods of application of insulating coatings; 3) various technological measures; 4) high-efficiency and economical pipes; 5) reliable and timely methods of inspection of existing pipelines without disturbing their mode of operation $[1,12]$.

One of the important methods to reduce corrosion of oil and gas equipment is to use of steel alloys and nonferrous alloys, but their high cost limits widespread use of this highly effective method of corrosion control [1].

\footnotetext{
* Corresponding author: dmytr.v@gmail.com
} 
Application of protective coatings in the fight against corrosion is also not widely used in practice. Metal coatings do not have sufficient protective properties under acid treatments at high temperatures, and are particularly sensitive to voltage concentrators. Nonmetallic coatings are not capable to provide the required pipe surface insulation against corrosive agents and are merely a substrate for a thicker coating film of glass, enamel or polymer [12].

Inhibitory protection is environmentally sustainable in the future and one of the simplest, most effective and in many cases economically feasible methods of corrosion control [13-16]. Its undoubted advantage is the possibility of application without change of the corresponding technological processes and hardware design on already existing industrial projects. Other protection measures usually require replacement of existing equipment with new ones, which entails significant capital expenditures.

Therefore, it is advisable to consider the problem of selecting corrosion inhibitors to reduce the corrosive effect on gas equipment and the importance of laboratory research in solving this problem.

\section{Problem statement}

The results of laboratory tests are an important and objective measure of the rate of corrosive hazardous fluids action and are the basis for planning, analyzing, conducting and evaluating the results of anti-corrosion measures (in particular, the use of corrosion inhibitors). The higher the level of laboratory research used to select a corrosion inhibitor, the more reasonable are conclusions as to expediency of its use and, as a consequence, more targeted corrosion measures will be planned.

A distinctive feature of industrial piping systems is branching, presence of different diameters sections, a considerable number of local hydraulic resistances (latches, elbows, inserts, compensators, etc.). In addition, industrial pipelines are characterized by a continuous change in costs, phase and chemical composition of the transported products. The consequence of this is the instability and unpredictability of corrosive aggressiveness of the environment, localization of corrosion damage both along the route and along the intersection of pipes $[14,15]$. All this causes the complexity of inhibitors choice problem and the technology of their application, the need for constant monitoring of effectiveness and sets up special demands to corrosion inhibitors themselves.

Corrosion inhibitors for industrial piping systems should be characterized by:

1) high protective properties in environments with constantly variable (sometimes in a wide range) chemical composition and hydrodynamic flow characteristics;

2) implementability - the possibility to use in existing technological schemes; stability of properties in processes of storage and use, taking into account climatic characteristics of a region;
3) cost-effectiveness - reagents should have an optimal price / quality ratio, taking into account the risks of operating specific industrial pipelines;

4) indifference - they should not have a negative impact on processes of transportation and processing of hydrocarbon products.

Almost all commercially manufactured corrosion inhibitors have their own sphere of application. This sphere is limited by technological features of equipment which is protected and by composition of corrosive active mediums.

The available range of modern corrosion inhibitors for oil and gas industry determines need for sound technological and economic choice of reagents, taking into account the operation peculiarities of various types of industrial pipelines. Laboratory researches play an important role in this selection. During laboratory process the following tasks are solved:

- simulation of corrosion processes in a real pipeline;

- detection of corrosion mechanism of steel grades of pipe;

- testing of inhibitor - selection of the most effective reagents for specific objects, specification of technology of their application;

- the identification of optimal application areas for specific inhibitor.

Therefore, selection of inhibitors for a specific oil and gas industry pipeline, or system of pipelines includes such stages:

1) analysis of technological characteristics of sites or system of industrial pipelines;

2) advance determination of reagents range, which suit to these conditions;

3) analysis of technological and anticorrosive features of inhibitors in laboratory conditions to detect the most effective ones;

4) bench and pilot tests of selected inhibitors.

The adoption of feasible practices of laboratory tests procedure for cleaning pipelines is shown schematically in Fig. $1[9,14,15]$.

Requirements for reagents and inhibition technology

Solubility / ability to disperse in aqueous or hydrocarbon media

Protective action in aqueous mineralized environment

Assessment of interphase distribution, efficiency in water-oil mixtures

Protective properties taking into account dynamics of flow

Conclusions on effectiveness field of application range

Fig. 1. Laboratory tests procedure for selection of corrosion inhibitors for gas pipelines. 


\section{Materials and methods}

Brief characteristics and features of the methodology for conducting experiments on the selection of corrosion inhibitors in laboratory conditions are presented below. Work results carried out on the selection of corrosion inhibitors for the conditions of industrial pipelines of the Kaverdinsky gas condensate deposites, where the problem of carbon dioxide corrosion is acute, are submitted as an example. In addition, wells operation and industrial equipment are complicated by intensive hydrate formation. Corrosive activity of the transported medium by industrial pipelines is significant due to the high mineralization of water as a result of the use of bischofite solutions as hydrate formation inhibitor and the content of aggressive components $\mathrm{CO}_{2}$ (up to $5.3 \%$ ).

In laboratory conditions, studies were conducted on the selection of a corrosion inhibitor for conditions when bischofite is used as a hydrate formation inhibitor.

Bischofite solution has better antihydrate activity than calcium chloride, and no worse than methanol [17]. Currently, significant reserves of anhydrous magnesium chloride have been discovered in the Dnieper-Donets Rift; within borders of the Orchikivsk Depression, the estimated resources are about 10 billion tons. Commercially it is produced by washing mineral deposits of bischofite through a well. The cost of bischofite is much lower than methanol and calcium chloride. Bischofite is a nonvolatile, ecologically sustainable reagent [113].

Bischofite solution with a mass fraction of $24 \%$ $\mathrm{MgCl}_{2}+3 \mathrm{~g} / \mathrm{dm}^{3} \mathrm{CH}_{3} \mathrm{COOH}$ was used to study effectiveness of the corrosion inhibitors. Concentration of acetic acid was chosen because of the maximum content of low molecular weight carboxylic acids in the formation waters of wells of Northeastern Ukraine. Lighted condensate was used as hydrocarbon phase, as it has neutral reaction of medium and constant fractional composition and as gaseous medium, carbon dioxide or oxygen.

Solubility of the reagents in the simulated medium was visually evaluated. Ability of reagents to form real or colloidal solutions and their stability were evaluated. As a result, 16 cationic and amphoteric surface-active substances were selected from more than one hundred surface-active substances that are highly soluble in aqueous solution. This indicates that the use of all reagents is possible in industrial gas pipelines transporting waterlogged products due to their high protective properties.

Thus, surfactants requirements were: 1) chemical structure of surfactants based on fundamental theoretical concepts; 2) coagulative stability in bischofite solution; 3) slight foaming; 4) protective anticorrosive action in hydrous mineralized waters; 5) thermal stability; 6) nontoxicity and safety for personnel and environment; 7) economic efficiency during industrial use.

The next stage is selection of reagents for protective properties based on evaluation of inhibitors protective effect in aqueous mineralized media ("bubble test"), rejection of ineffective ones, determination of applications spheres with respect to composition of aqueous medium and preliminary determination of working dosages.

Research and evaluation of the protective effect of inhibitors was carried out in accordance with GOST 9.905-82 "Methods of corrosion tests. General requirements", GOST 9.502-82 "Metal corrosion inhibitors for water systems. Methods of corrosion tests", GOST 9.506-87 "Inhibitors of metal corrosion in water-oil environments".

Corrosive aggressiveness of the medium was evaluated by gravimetric method, according to loss of samples mass. Control experiment was without addition of reagents.

Corrosion tests were carried out on steel P-110 (table 1). This type of steel is widely used for tubing.

Table 1. Chemical composition of steel P 110.

\begin{tabular}{|c|c|c|c|c|c|c|c|}
\hline $\mathbf{C}$ & $\mathbf{S i}$ & $\mathbf{M n}$ & $\mathbf{P}$ & $\mathbf{S}$ & $\mathbf{C r}$ & $\mathbf{N i}$ & $\mathbf{C u}$ \\
\hline $0.26-$ & $0.17-$ & - & $\leq 0.02$ & $\leq 0.01$ & $\begin{array}{c}0.80- \\
1.10\end{array}$ & $\leq 0.20$ & $\leq 0.20$ \\
0.395 & 0.37 & & & & & \\
\hline
\end{tabular}

Corrosion studies were carried out in a thermostatic installation (Fig. 2.) The installation is designed at the All-Union Scientific Research Institute of Natural Gases and Gas Technologies (VNIIGAZ) for determination of corrosion rate in the simulated conditions of industrial pipelines [18]. It is a glass vessel in which the test solution was poured and a fluoroplastic cylinder with witness samples and a propeller stirrer was placed.

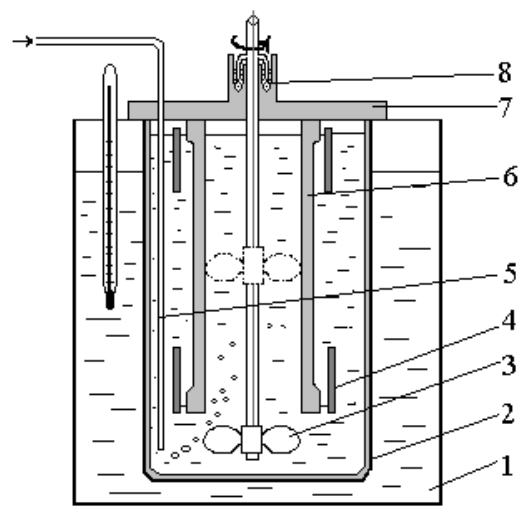

Fig. 2. Installation diagram for corrosion research:

1 - thermostat; 2 - glass chamber; 3 - mixer; 4 - metal piece;

5 - gas supply tube; 6 - fluoroplastic cylinder; 7 - cap;

8 - hydraulic seal.

The cell was attached to an electric motor that rotated the stirrer. During rotation of the stirrer, circular fluid motions in the laminar mode were created in the fluoroplast cylinder with a flow rate of $0.3-0.5 \mathrm{~m} / \mathrm{s}$. When the propeller was mounted below the bottom of the cylinder, it was rotated at a speed of 1400 revolutions per second. There was a circular motion of the fluid in turbulent mode. The speed of stream flow in the area of placement of metal piece was $7-8 \mathrm{~m} / \mathrm{s}$. In addition to circular motion, fluid was also circulated through the small cylinder by creating irritation during rotation of the stirrer.

The corrosion rate of the metal was calculated by the formula $[18,19,20]$ : 


$$
v=\frac{\Delta m}{S \tau}
$$

where $v$ - the corrosion rate $\mathrm{g} /\left(\mathrm{m}^{2} \mathrm{~h}\right)$;

$\Delta m$ - the loss of the metal piece, $\mathrm{g}$;

$S$ - the surface area of the coupon, $\mathrm{m}^{2}$;

$\tau$ - the test duration, $\mathrm{h}$.

Protective effect of test reagents in bischofite solution $(Z)$ was calculated by the formula $[18,19]$ :

$$
Z=\frac{v_{0}-v_{1}}{v_{0}} 100
$$

where, $v_{0}$ - corrosion rate of the metal piece without the corrosion inhibitor $\mathrm{e}, \mathrm{g} /\left(\mathrm{m}^{2} \cdot \mathrm{h}\right)$;

$v_{1}$ - corrosion rate of the metal piece with the corrosion inhibitor $\mathrm{e}, \mathrm{g} /\left(\mathrm{m}^{2} \cdot \mathrm{h}\right)$.

Average permeability is calculated according to the mass loss [20]:

$$
P=8.76 \cdot v / \gamma
$$

where $P$ - permeability, $\mathrm{mm} /$ year;

8.76 - the conversion coefficient;

$v$ - the corrosion rate, $\mathrm{g} /\left(\mathrm{m}^{2} / \mathrm{h}\right)$;

$\gamma$ - metal density, $\mathrm{g} / \mathrm{cm}^{3}$.

Quantitative indicators of the experiments were analyzed by methods of mathematical statistics with the calculation of average sample values, variance and errors of average values in groups of indicators. The significance of differences in the results obtained for different groups was determined by Student's t-test. Differences were considered statistically proven with a generally accepted probability of error $p<0.05$.

Based on the results of preliminary studies, the following reagents were selected for further experiments: corrosion inhibitor KI-1M, cationic surfactants Stentex (St), Sulforocanol (SRK), amphoteric surfactants Emily (EM) and Cocamidpropylbetaine (KAPB):

KI-1M - acid corrosion inhibitor, cationic surfactant, a mixture of catapine and urotropine;

Stentex (St) - cationic surfactant, quaternary ammonium compound;

Sulforocanol (SRK) - cationic surfactant with the general formula $\mathrm{R}-\mathrm{O}-\left(\mathrm{C}_{2} \mathrm{H}_{4} \mathrm{O}\right)_{2}-\mathrm{SO}_{3}$, where $\mathrm{R}=\mathrm{C}_{\mathrm{n}} \mathrm{H}_{2 \mathrm{n} \div 1} ; \mathrm{n}=12 \div 14$ and a molecular weight of about 388.

Emily (EM) - amphoteric surfactant, the mixture of sodium and magnesium salts of lauryl and oleyl alcohols estersulfates;

Cocamidpropylbetaine (KAPB) - amphoteric surfactant, the fatty acid amide derivative with betaine structure.

In order to identify the possibility of combined application of a hydrate inhibitor, bischofite which is used in the deposits, and corrosion inhibitors under study, protective properties of inhibitors in bischofite solutions with concentration of $24 \%$ of $\mathrm{MgCl}_{2}$ were determined.

\section{Research results}

The obtained dependences of corrosion rate on concentration which are shown in Fig. 3, 4, allowed to isolate the minimum required concentration of reagents, for the test reagents $-1-2 \mathrm{mg} / \mathrm{dm}^{3}$.

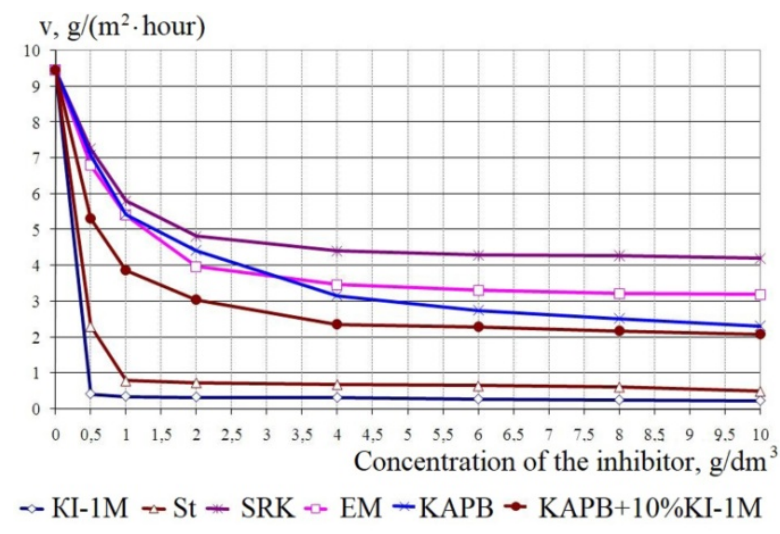

Fig. 3. Dependence of the corrosion rate of steel on the concentration of surfactants in bischofite solution in carbon dioxide environment $\left(w_{\mathrm{MgCl}_{2}}=24 \%, \mathrm{~T}=80^{\circ} \mathrm{C}, 3 \mathrm{~g} / \mathrm{dm}^{3}\right.$ $\mathrm{CH}_{3} \mathrm{COOH}, t=2 \mathrm{~h}$, volume fraction of condensate $25 \%$, $P_{\mathrm{CO}_{2}}=0.1 \mathrm{MPa}$.).

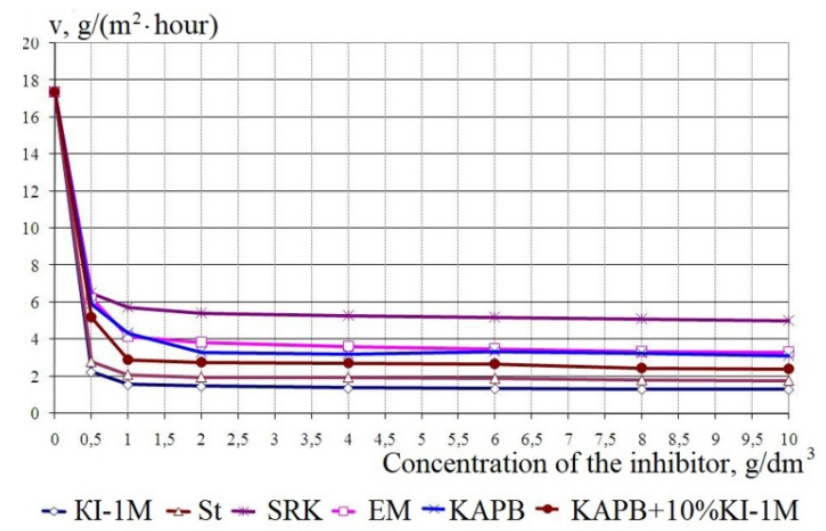

Fig. 4. Dependence of the corrosion rate of steel on the concentration of surfactants in bischofite solution in an oxygen environment $\left(w_{\mathrm{MgCl}_{2}}=24 \%, \mathrm{~T}=80{ }^{\circ} \mathrm{C}, 3 \mathrm{~g} / \mathrm{dm}^{3} \mathrm{CH}_{3} \mathrm{COOH}\right.$, $t=2 \mathrm{~h}$, volume fraction of condensate $25 \%, P_{O_{2}}=0.1 \mathrm{MPa}$.).

The highest inhibitory effect in bischofite systems low molecular weight carboxylic acids - carbon dioxide/oxygen at the content of reagents in a solution of $1 \mathrm{~g} / \mathrm{dm}^{3}$ revealed surfactants $\mathrm{KI}-1 \mathrm{M}$, St, respectively, $83.5-96.2 \%$ and $77.8-91.5 \%$ (Fig. 5). The remaining reagents have a lower degree of protection at the appropriate concentration.

Due to mathematical data processing, polynomial and power mathematical models were selected. In an environment with $\mathrm{O}_{2}$, polynomial equations (Equations 4) give a low level of reliability of parameters, the obtained reliability indicators for the coefficients significantly exceed the level of 0.05

$$
y=a_{0}+a_{1} x+a_{2} x^{2}+a_{3} x^{3}
$$

where, $y$ - corrosion rate, $\mathrm{g} /\left(\mathrm{m}^{2} \cdot \mathrm{h}\right)$;

$x$ - concentration of inhibitor, $\mathrm{g} / \mathrm{dm}^{3}$;

$a_{0}, a_{1}, a_{2}, a_{3}$ - empirical coefficients.

In $\mathrm{CO}_{2}$ environment, polynomial model in three cases out of six describes the experimental data as well 
as the power data (in the presence of SRK, EM, KAPB).

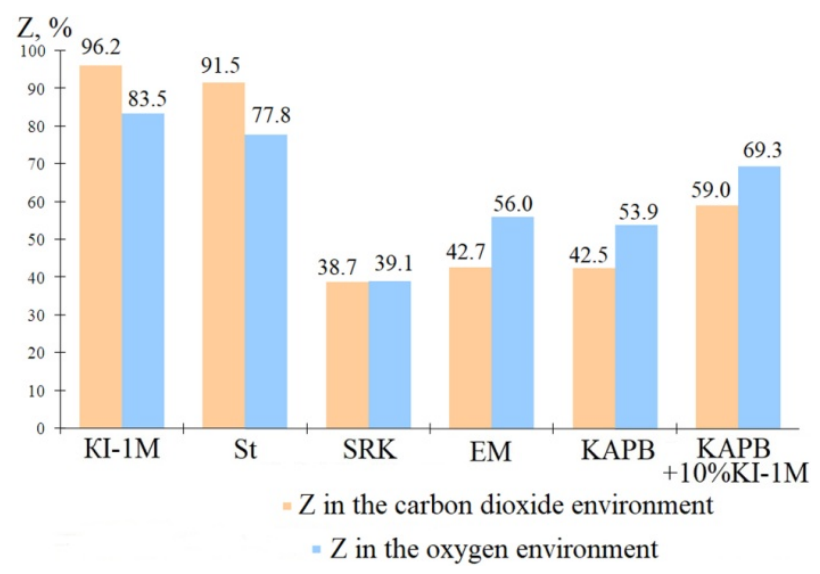

Fig. 5. Protective effect of test reagents in bischofite solution $\left(w_{\mathrm{MgCl}_{2}}=24 \%, \mathrm{~T}=80^{\circ} \mathrm{C}, 3 \mathrm{~g} / \mathrm{dm}^{3} \mathrm{CH}_{3} \mathrm{COOH}, t=2 \mathrm{~h}\right.$, concentration of surfactants $1 \mathrm{~g} / \mathrm{dm}^{3}$, volume fraction of condensate $25 \%, \mathrm{P}_{\mathrm{CO}_{2} / \mathrm{O}_{2}}=0.1 \mathrm{MPa}$ ).

It should be noted that, in addition to the correlation coefficient, an important indicator of the adequacy of the approximation model is a residual error. The smaller the residual error value, the more accurate the model describes the experimental data. In all cases, residual error when using the power function (Equation 5) is significantly smaller than when using the polynomial, which indicates a much higher quality of approximation. For all inhibitors, the coefficients of the equation are reliably determined by $p<0.05$

$$
y=b_{0}+\left(b_{1} x+b_{2}\right)^{-3}
$$

where, $y$ - corrosion rate, $\mathrm{g} /\left(\mathrm{m}^{2} \cdot \mathrm{h}\right)$;

$x$ - concentration of inhibitor, $\mathrm{g} / \mathrm{dm}^{3}$;

$b_{0}, b_{1}, b_{2}$ - empirical coefficients.

The coefficients and parameter estimates of nonlinear approximation equation are shown in Table 2, $p<0.05$.

Table 2. Coefficients and parameter of nonlinear approximation equation 5 .

\begin{tabular}{|c|c|c|c|c|c|c|}
\hline \multirow[t]{2}{*}{ Surfactant } & \multicolumn{3}{|c|}{$\begin{array}{l}\text { Equation } \\
\text { coefficients }\end{array}$} & \multicolumn{3}{|c|}{$\begin{array}{c}\text { Estimation of the } \\
\text { approximation equation } \\
\text { parameters }\end{array}$} \\
\hline & $b_{0}$ & $b_{1}$ & $b_{2}$ & $\boldsymbol{R}$ & $R^{2}$ & Residual error \\
\hline \multicolumn{7}{|c|}{ For the $\mathrm{O}_{2}$ environment } \\
\hline KI-1M & 1.35 & 1.28 & 0.34 & 0.999 & 0.9997 & 0.01 \\
\hline $\mathrm{St}$ & 1.85 & 1.24 & 0.40 & 0.999 & 0.9999 & 0.02 \\
\hline SRK & 5.21 & 0.93 & 0.43 & 0.999 & 0.9992 & 0.11 \\
\hline EM & 3.41 & 0.60 & 0.42 & 0.999 & 0.9992 & 0.13 \\
\hline KAPB & 3.21 & 0.60 & 0.41 & 0.999 & 0.9995 & 0.09 \\
\hline $\begin{array}{c}\text { KAPB+ } \\
\text { KI-1M }\end{array}$ & 2.49 & 0.65 & 0.41 & 0.999 & 0.9985 & 0.28 \\
\hline \multicolumn{7}{|c|}{ For the $\mathrm{CO}_{2}$ environment } \\
\hline KI-1M & 0.28 & 2.85 & \begin{tabular}{|l|l|}
0.48 \\
\end{tabular} & 0.999 & 0.9999 & 0.01 \\
\hline St & 0.57 & 0.74 & 0.48 & 0.999 & 0.9978 & 0.15 \\
\hline SRK & 4.16 & 0.26 & 0.57 & 0.999 & 0.9971 & 0.07 \\
\hline EM & 3.14 & 0.24 & 0.54 & 0.999 & 0.9977 & 0.08 \\
\hline KAPB & 2.35 & 0.15 & 0.52 & 0.998 & 0.9965 & 0.16 \\
\hline $\begin{array}{l}\text { KAPB+ } \\
\text { KI-1M }\end{array}$ & 2.20 & 0.32 & 0.52 & 0.999 & 0.9984 & 0.07 \\
\hline
\end{tabular}

Produced formation water is corrosive-aggressive phase of extracting fluid. So the efficiency of complex systems (bischofite $24 \% \mathrm{MgCl}_{2}+$ surfactants $0.1 \%$ ) in relation to simulated medium of formation water is determined. The obtained data show (Fig. 6) that bischofite solution inhibits the process of carbon dioxide corrosion. All complex systems under study provide a degree of metal protection over $90{ }^{\circ} \mathrm{C}$.

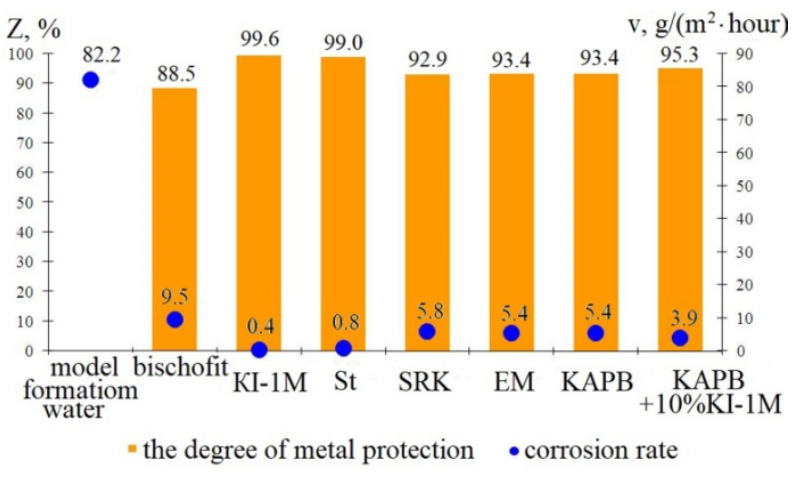

Fig. 6. Protective action of bischofite-based complex inhibitors against the reservoir model environment water $\left(w_{\mathrm{MgCl}_{2}}=24 \%\right.$, $\mathrm{T}=80{ }^{\circ} \mathrm{C}, 3 \mathrm{~g} / \mathrm{dm}^{3} \mathrm{CH}_{3} \mathrm{COOH}, \mathrm{t}=2 \mathrm{~h}$, concentration of surfactants $1 \mathrm{~g} / \mathrm{dm}^{3}$, volume fraction of condensate $25 \%$, $P_{\mathrm{CO}_{2}}=0.1 \mathrm{MPa}$ ).

Comparative analysis of the data indicates the feasibility of using bischofite solution with a mass fraction of $24 \%$ of $\mathrm{MgCl}_{2}$ and the addition of a corrosion inhibitor $0.1 \% \mathrm{KI}-1 \mathrm{M}$ for protection of industrial gas pipelines from carbon dioxide corrosion, as long as this system provides a degree of protection against corrosion $99.6 \%$ relatively to stimulated medium of formation waters.

The results of industrial tests at the Kaverdinsky gas condensate deposits confirmed the efficiency of the complex system (bischofite solution with a mass fraction of $24 \%$ of $\mathrm{MgCl}_{2}$ and the addition of a corrosion inhibitor $0.1 \% \mathrm{KI}-1 \mathrm{M}$ ). Rate of uniform corrosion with constant circulation of the inhibitor in the system did not exceed $0.01 \mathrm{~mm} /$ year.

The influence of the reagents on the corrosion rate and their protective effect in the simulated medium of formation waters was investigated. All tested surfactants in the simulated of formation water show a protective effect of more than $90 \%$ with a dosage of $1 \mathrm{~g} / \mathrm{dm}^{3}$ (Fig. 7), which satisfies the requirements of regulatory documents for corrosion inhibitors and allows them to be recommended for application at gas-fired facilities.

The protective properties of surfactants in the bischofite environment are 1.0-2.5 times less effective (Fig. 7). The protective effect of surfactants: SRK, EM and CAPB is especially noticeably reduced by $2.2-2.5$ times. The KI-1M reagent in bischofite solutions practically does not change its effectiveness (increases by 1.1 times). A degree of protection of more than $90 \%$ was detected in the presence of surfactants St and $\mathrm{KI}-1 \mathrm{M}$. In this regard, the use of SRK, EM and CAPB is appropriate for industrial gas pipelines that transport products with is low-mineralized aquatic environment. 


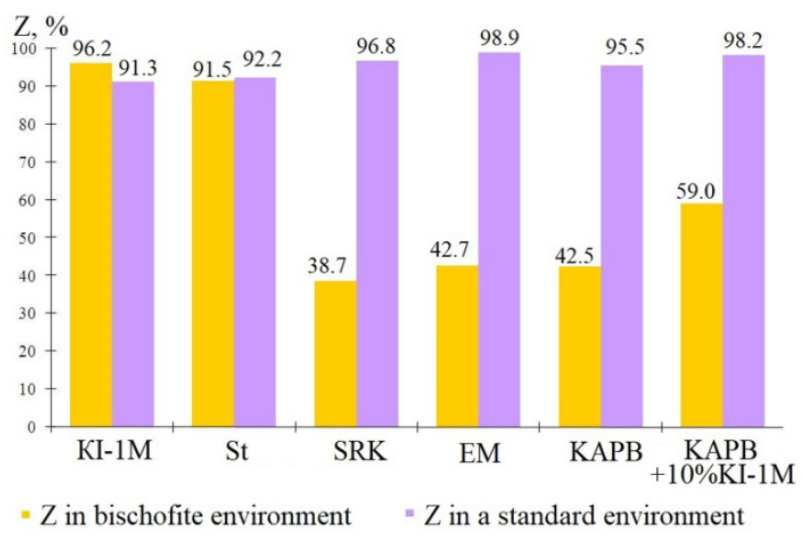

Fig. 7. The degree of corrosion protection in bischofite solutions and simulated environment of formation water with a mass fraction of surfactants $0,1 \%$ (the inhibitor concentration is $1 \mathrm{~g} / \mathrm{dm}^{3}, \mathrm{~T}=80^{\circ} \mathrm{C}, 3 \mathrm{~g} / \mathrm{dm}^{3} \mathrm{CH}_{3} \mathrm{COOH}, \mathrm{t}=2 \mathrm{~h}$, concentration of surfactants $1 \mathrm{~g} / \mathrm{dm}^{3}$, volume fraction of condensate $25 \%$, $\left.P_{\mathrm{CO}_{2}}=0.1 \mathrm{MPa}\right)$.

The obtained values of corrosion rate can be explained by the fact that the surfactants SRK, EM, and KAPB are capable of complexing with metals and are partially spent on the formation of complex compounds with magnesium and calcium ions which are in bischofite solution (Equations 6)

$$
M e+J R \leftrightarrow M e R J
$$

where, $M e$ - the solvated metal ion;

$J$ - an inorganic surfactant ion;

$R$ - the hydrocarbon ion of the surfactant.

Nitrogen-containing surfactants KI-1M and St form a hydrophobic film on the surface of metal. This film is a barrier that shields the metal-corrosive environment. In most cases, surfactants are less polar than the components of the bulk phase, or have a low-polar radical. When adsorbed, surfactants replace polar surface with a less polar layer, equalizing polarity difference [15].

The effectiveness of complex inhibitors with respect to simulating environment of formation water in Northeastern Ukraine is represented in Figure 7. Data show that the corrosion rate in the bischofite solution is less than in the simulated medium of formation waters. The corrosion rate in the simulated medium of formation waters is $82.2 \mathrm{~g} /\left(\mathrm{m}^{2} \cdot \mathrm{h}\right)$, and in bischofite solution $9.5 \mathrm{~g} /\left(\mathrm{m}^{2} \cdot \mathrm{h}\right)$ (Fig. 6) [19]. Such results are explained by the different concentrations of salts in the compared media and the different properties of the two salts $\left(\mathrm{MgCl}_{2}\right.$ and $\left.\mathrm{NaCl}\right)$ in the high humidity environment. $\mathrm{NaCl}$ is more corrosive under immersion environment [21].

All investigated complex systems provide a degree of metal protection of more than $90{ }^{\circ} \mathrm{C}$.

Thus, laboratory experiments to investigate the technological and corrosion properties of corrosion inhibitors are an important step in the selection of corrosion inhibitors for specific pipeline systems and sections. Despite the difficulty of accurately reproducing the technological conditions of corrosion of gas pipelines at the stage of laboratory experiments in condition of a competent methodological approach to the experiments, it is possible to identify reagents that meet the requirements for their protective and technological properties to protect a specific gas industry.

It should be noted that laboratory testing is only the first step in the selection of an inhibitor - it allows to screen out the ineffective and to select the best ones for the next bench and industrial research. Laboratory testing is carried out under more severe conditions than actual tests (overestimated concentrations of $\mathrm{CO}_{2}$ and $\mathrm{O}_{2}$, short exposure time of the metal piece), so that the degree of protection is reduced compared to the real one.

Industrial tests of complex inhibitors proposed by the author for improvement of gas wells reliability under conditions of hydration and corrosion, were conducted at the Kaverdinsky gas condensate deposits of CJSC "Plast" for 30 days. The effectiveness of the complex inhibitor in preventing hydration was determined by monitoring the operation of well № 2 in hydration mode without supplying the inhibitor. The dew point of gas was determined by "Kharkov-2M" hydrometer, and the corrosion intensity was based on the testimonials that were installed in the samplers at the wellhead. Corrosion rate at constant circulation of the inhibitor in the system did not exceed $0.01 \mathrm{~mm} /$ year.

\section{Conclusions}

1. The basis of a complex inhibitor of hydrate formation and corrosion can be ecological sustainable bischofite solutions with the addition of amphoteric and cationic surfactants.

2. In order to reduce the corrosion effect of concentrated bischofite solution on the gas equipment of the Kaverdinsky gas condensate deposits, KI-1M and St inhibitors were selected, the inhibition efficiency of which in carbon dioxide and oxygen environment is $83.5-96.2 \%$ and $77.8-91.5 \%$ respectively. The results of industrial tests confirmed the effectiveness of the complex system - bischofite solution with a mass fraction of $\mathrm{MgCl}_{2} 24 \%$ and the addition of a corrosion inhibitor KI-1M $0.1 \%$ ). The rate of uniform corrosion at constant circulation of the KI-1M inhibitor in pipelines did not exceed $0.01 \mathrm{~mm} /$ year.

3. The cationic surfactants KI-1M, St, SRK and amphoteric surfactants EM and KAPB effectively protect in a reservoir modeling environment and provide a degree of protection from carbon dioxide corrosion of 91.2-98.9\%.

\section{References}

1. M. Finšgar, J. Jackson, Application of corrosion inhibitors for steels in acidic media for the oil and gas industry: A review. Corros. Sci. 86, 17-41 (2014). doi.org/10.1016/j.corsci.2014.04.044

2. Z. Panossian, N.L.d. Almeida, R.M.F.d. Sousa, G.d.S. Pimenta, L.B.S. Marques, Corros. Sci. 58, 1 (2012) 
3. M.M. Osman, M.N. Shalaby, Mater. Chem. Phys. 77, 261 (2003)

4. P.C. Okafor, X. Liu, Y.G. Zheng, Corros. Sci. 51, 761 (2009)

5. S. Nešic', W. Sun, in Shreir's Corrosion, ed by J.A.R. Tony (Elsevier, Oxford, 2010), pp. 12701298

6. A.N. Serebryakov, I.S. Motuzov, Corrosion of oilfield equipment and anticorrosion techniques applied on the Karakuduk oilfield (Western Kazakhstan). RUDN J. Eng. Res. 18(2), 174-181 (2017). doi:10.22363/2312-8143-2017-18-2-174181

7. A. Groysman, Corrosion problems and solutions in oil, gas, refining and petrochemical industry. Koroze Ochr. Mater. 61(3), 100-117 (2017). doi:10.1515/kom-2017-0013

8. J. Wang (ed.), Mechanism and modelling of $\mathrm{CO}_{2}$ corrosion on downhole tools (R. Soc. Open. Sci., 2019). doi:10.1098/rsos.181899

9. C. Rena, D. Liub, Z. Baic, T. Lia, Mater. Chem. Phys. 93(2-3), 305 (2005)

10. X. Hu, A. Neville, Wear 267(11), 2027 (2009)

11. M.A. Migahed, I.F. Nassar, Electrochim. Acta 53, 2877 (2008)

12. M. Askari, M. Aliofkhazraei, S. Ghaffari, A. Hajizadeh, J. Nat. Gas. Sci. Eng. 58, 92 (2018)

13. E.R. Hajrullina, Opyt i perspektivy ingibitornoj zashity neftepromyslovogo oborudovaniya (Experience and prospects of inhibitory protection of oilfield equipment). (Neftegazovoe delo, 2004), http://www.ogbus.ru/authors/Hairullina/Hairullina_1 .pdf. Accessed 28 Nov 2019

14. B.J. Usman,-S.A.A. Arab, Carbon Dioxide Corrosion Inhibitors: A review. J. Sci. Eng. (2017). doi: 10.1007/s13369-017-2949-5

15. H. Akrout, L. Bousselmi, E. Triki et al., J. Mater. Sci. 39(24), 7341 (2004)

16. A.A. Turdymatov, N.H. Abdrahmanov, Effektivnost himicheskoj ingibitornoj zashity $v$ borbe $s$ vnutrennej korroziej promyslovyh truboprovodov (Efficiency of chemical inhibitor protection in the fight against the internal corrosion of industrial pipelines). (Neftegazovoe delo, 2016), http://ogbus.ru/files/ogbus/issues/3_2016/ogbus_3_2 016_p137-156_TurdymatovAA_ru.pdf

17. V.A. Istomin, Preduprezhdenie $i$ likvidatsiya gazovyih gidratov $v$ sistemah sbora i promyislovoy obrabotki gaza i nefti (Prevention and elimination of gas hydrates in the systems of collection and field processing of gas and oil). (VNIIGAZ, Moscow, 1990)

18. I.G. Zezekalo, Razrabotka i primenenie ingibitorov dlya zaschityi ot korrozii gazopromyislovogo oborudovaniya $v$ srede prirodnogo gaza $s$ povyishennyim soderzhaniem karbonovyih kislot (Development and application of inhibitors for corrosion protection of gas-field equipment in natural gas with a high content of carboxylic acids). Dissertation, VNIIGAZ, 1986

19. V.I. Dmytrenko, Pidvyshchennia nadiinosti ekspluatatsii hazokondensatnykh rodovyshch $v$ umovakh vuhlekyslotnoi korozii $i$ hidratoutvorennia iz zastosuvanniam kompleksnoho inhibitoru na osnovi bishofitu (Improving the reliability of operation deposits in gas and condensate conditions the of carbon dioxide corrosion and hydrate formation with the use of complex inhibitor on the basis of bischofite). Dissertation, Ivano-Frankivsk National Technical University of Oil and Gas, 2009

20. N. Atanov (ed.), Pipelines corrosion during water supply process. 2018 IOP Conf. Ser.: Mater. Sci. Eng. 365(4) (2018). doi:10.1088/1757899X/365/4/042073

21. Y. Xi, Z. Xie, Report No. CDOT-DTD-R-2002-4. (Colorado Department of Transportation, 2002), https://pdfs.semanticscholar.org/3f24/71d55291bbd7 84b47aa59d9de9955e7519fd.pdf. Accessed 28 Nov 2019 